\title{
Mantle flow and migration at the Rodrigues Triple Junction
}

\author{
CHRISTINE MARIE MEYZEN ${ }^{1}$, GUILLAUME JACQUES ${ }^{2}$, \\ FOLKMAR HAUFF $^{3}$, MARCEL REGELOUS ${ }^{4}$, RENÉ H.W. \\ ROMER $^{5}$ AND ULRICH SCHWARZ-SCHAMPERA ${ }^{6,7}$ \\ ${ }^{1}$ Università degli Studi di Padova \\ ${ }^{2}$ Federal Institute for Geosciences and Natural Ressources \\ ${ }^{3}$ GEOMAR Helmholtz Centre for Ocean Research Kiel \\ ${ }^{4}$ GeoZentrum Nordbayern, Friedrich-Alexander-Universität \\ (FAU) Erlangen-Nürnberg \\ ${ }^{5}$ GeoZentrum Nordbayern, Friedrich-Alexander-Universität \\ Erlangen \\ ${ }^{6}$ Federal Institute for Geosciences and Natural Resources \\ ${ }^{7}$ International Seabed Authority \\ Presenting Author: christine.meyzen@unipd.it
}

Near the Rodrigues Triple Junction (RTJ), marked changes in virtually all aspects of crustal accretion occur, as this junction connects three ridges with contrasting spreading rates and morphotectonic segmentations: the ultra-slow-spreading Southwest Indian Ridge (SWIR), and the intermediate-spreading Central (CIR) and Southeast Indian (SEIR) ridges. Near the junction, the SWIR morphotectonic segmentation is among the deepest and most chaotic ever surveyed among the global MOR system, while those of the CIR and SEIR limbs exhibit shallower and more subdued axial topographic variations. At the junction, the oblique north-eastward SWIR lengthening in response to unsteady collinearity between the SEIR and CIR is episodically compensated by the southward propagation of the CIR and alternative stages of receding and propagation of the SEIR leading to an apparent length constancy of its first segment for the last Myrs. These multiple ridge propagation episodes, from both north, west and east suggest mantle migration towards the RTJ. The sharp mantle temperature contrast inferred from seismic wave variations between relatively warm mantle beneath the SEIR and the eastern CIR flank to a colder mantle underneath the SWIR is expected to result in the development of sustained mantle flow and deviation of residual mantle column toward the region of cooler mantle. Here, we present new major, trace element and $\mathrm{Sr}-\mathrm{Nd}-\mathrm{Hf}-\mathrm{Pb}$ isotope data for on- and off-axis MORB sampled over the SEIR and CIR propagators during INDEX exploration cruises. The comparison of the chemical attributes of SEIR MORB with their unusual counterparts from the SWIR tip points to a melting derivation of SWIR MORB by advancement of newly SWIR mantle into a vertically heterogeneous SEIR residual melting column. The compositional transition in major and trace elements and $\mathrm{Pb}-\mathrm{Sr}-\mathrm{Nd}-\mathrm{Hf}$ isotopes along the SWIR at about $\sim 80 \mathrm{~km}$ from the RTJ is closely related to the transition in morphological segmentation between a highstrain, chaotic SWIR domain where blocks of pre-existing SEIR/CIR seafloor are dissected by nascent north-eastward propagating rifts toward the progressive establishment of more normal seafloor processes. 